\title{
Reflections on the Reform of College Physical Education in the New Period
}

\author{
Xudong Wang ${ }^{1 a^{*}}$, Yuxin $\mathrm{CaO}^{2 b^{*}}$ \\ ${ }^{1}$ Sports Department, Shaanxi University of Chinese Medicine, Xian yang, Shaanxi, China \\ ${ }^{2}$ Student, Shaanxi University of Chinese Medicine \\ Corresponding author.Email: $a^{*} 790086212 @ q q$. .com $^{b^{*}} 1132421538 @ q q . c o m$
}

\begin{abstract}
With the continuous development of China's social economy, new educational ideas emerge in an endless stream, and the reform of college physical education teaching reform has entered a new stage. Various measures have been taken to promote the reform of college physical education, focusing on cultivating college students equipped with the idea of lifelong physical education. After the efforts of related departments and sports workers, the reform of college physical education has achieved some results, but there are still many problems. In this study, the connotation and purpose of college physical education and the existing problems in the current physical education reform are analyzed, and the corresponding improvement measures are put forward.
\end{abstract}

Keywords: College sports, Education reform, Thinking, the new period

\section{INTRODUCTION}

As far as physical education reform is concerned, domestic scholars have analyzed the construction of talent training mode for physical education major, in conjunction with basic physical education, higher education and other related contents, and put forward relevant policy suggestions. This study mainly analyzes the problems existing in the reform of college physical education, and puts forward corresponding countermeasures and methods in view of these problems.

\section{THE CONNOTATION AND PURPOSE OF COLLEGE PHYSICAL EDUCATION}

\subsection{Connotation of college physical education}

College students can further master the basic knowledge, principles, skills and techniques related to physical education, so that students can have good physical ability and establish the concept of lifelong physical education, which is called college physical education [1]. Specifically, it is necessary for college students to understand the impact of physical exercise on human health and realize the important value of physical education in the current social and economic development, so that they can realize the importance of health and physical education from a relatively novel perspective and improve their quality of life through physical exercise. It is also essential for students to obtain some basic methods and principles in the process of carrying out college sports, such as mental health, body shape and exercise principles, so that they can understand the positive effect of physical exercise on them, arrange their rest time and load time reasonably, and do a good job in self-exercise monitoring activities.

\subsection{The purpose of college physical education}

The most fundamental purpose of carrying out physical education activities for college students is to enhance their physical quality, so that they can realize the purpose of healthy growth, so as to provide comprehensive quality talents with good quality in all aspects for the socialist construction in the new era. The development of college physical education courses has a lot of positive effects on college students, such as allowing college students to have a more comprehensive and in-depth understanding of physical exercise, updating their traditional concept of physical education, and helping them broaden their physical vision. As far as the school is concerned, physical education is an important component of the whole education system carried out by the school, and it has undertaken the important mission of training high-quality talents in the new era. Some scholars point out in the research that it is necessary to help college students establish the 
concept of lifelong sports, because all kinds of sports activities carried out by the school need to play a role not only in the students' school life, but also in their whole life. In fact, college physical education is also an important component of lifelong physical education [2].

\section{ANALYSIS ON THE REFORM OF COLLEGE PHYSICAL EDUCATION IN THE NEW ERA}

After the founding of the People's Republic of China, we can find that good results have been achieved in all aspects of college education reform, no matter from theory to practice or from teaching concepts to relevant teaching methods. However, we can still find that there are many defects in the current reform of college physical education. For example, the reform only stays on the surface and rarely involves the actual problems faced by college physical education. This has a very negative impact not only on the development of the teaching task of college physical education, but also on the realization of the goal of China's physical education reform. At present, China is still in a critical stage of transformation. With the change of politics, culture and economy, the goal and theoretical system of college physical education will also change accordingly. In the face of new demands from various aspects, college physical education activities must actively meet new challenges and get further development [3]. In the process of analyzing the relevant content of China's university physical education, we found that there are still many deficiencies. These problems and deficiencies were analyzed as follows in so as to find out the relevant reform plan to ensure the smooth implementation of the related process of China's university physical education reform. Due to the influence of the traditional education idea, there are many problems in the reform of college physical education in China. The problems are as follows:

\subsection{Lack of relevant theoretical basis}

In recent years, many theoretical defects have been found in the reform of college physical education in China, which has a great adverse effect on the improvement of the quality of college physical education. At present, there is still a lack of authoritative, systematic and scientific basic theory in China's college physical education. In the specific practice of reform, some so-called authoritative concepts were blindly introduced and some new terms were deliberately used, even new nouns were invented to cooperate with their use. These practices are not real theoretical innovations to substantially promote the reform of university physical education, just make the theoretical system of college physical education more chaotic [4]. The lack of systematic and scientific theoretical knowledge makes it difficult to take scientific theories as guidance in the specific practice activities of college physical education, and also makes the reform of college physical education more blind and random, which has a negative impact on the orderly reform of college physical education.

\subsection{Laggard educational concepts and methods}

With the rapid development of college physical education in recent years, more and more social subjects pay more attention to the reform of college physical education. However, the late start of reform and the relatively old teaching ideas used in the college physical education have make the reform difficult to change and innovate for a long time. The development of college physical education activities has been affected by some concepts related to the body constitution education. Many college students think that the purpose of physical education is just to exercise their body, and they do not pay attention to the role of college physical education in quality.

At the same time, in the college physical education teaching activities, the teaching concept adopted by the teachers is relatively backward. They still regard the teachers as the center of educational activities, pay too much attention to physical education skill training and intensity training, and still adopt the instillation teaching method, which makes the whole class dull and monotonous. In terms of teaching methods, teachers still adopt the traditional teaching methods such as integrated and decomposing teaching method, or explanation and demonstration teaching method, which are not interesting and innovative enough. Thus, students will be in a passive position in physical education teaching [5]. It is precisely because of the outdated methods and concepts that the participation initiative and enthusiasm of college students are affected in the physical education, which has a negative impact on their fitness and entertainment, life-long education and edification of sentiment. Therefore, it can be concluded that the backward teaching methods and concepts are serious problems in the current reform of college physical education in China.

\subsection{Outdated curriculum setting and system}

At present, the content of college sports training courses is outdated and separated from the actual demand of the market. As a result, the university sports training curriculum is not systematic enough and not in line with the market demands, which has a significant adverse impact on the long-term development of the university sports training curriculum $t$. In the current social environment, the overall development momentum of the sports industry is relatively good. In the market, there is a large demand for sports talents such as sports agents and club coaches [6]. But the university physical 
education courses mainly trained the physical education students with the nature of 'normal'. The sports talents cultivated are mismatched with the social demand, which will not only affect the employment situation of sports students, but also lead to the unsatisfied demand for sports talents in the market.

At the same time, the textbooks used in the college physical education curriculum system remain unchanged for several years, which needs to be updated and adjusted in real time according to the change of market demand. This situation makes the theoretical knowledge learned by students is difficult to play a greater role and value in the concrete practice.

\subsection{Students' quality development is one-sided}

In the process of $\mathrm{PE}$ curriculum development, it is necessary for students to obtain comprehensive qualities. Students not only need to master solid theoretical knowledge and professional sports skills, but also need to develop leaping thinking and attention. This can help the students achieve the best level of sports training and improves the overall development level of college physical education. However, the development of students' quality is still one-sided in general in the course of physical education in colleges and universities. It behaves as: the students have mastered the good physical education theory knowledge and skills, but the students' own management ability is not enough, innovation quality and concentration are insufficient. The main reasons for this situation are as follows: First, the source of students is uneven; Second, there are shortcomings in teachers' guidance of students' outlook on life and self-discipline. In the current society, the demand for sports talents is getting higher and higher, especially for sports talents with higher comprehensive quality.

\section{ANALYSIS OF THE METHODS AND COUNTERMEASURES OF COLLEGE PHYSICAL EDUCATION REFORM IN THE NEW PERIOD}

\subsection{Innovate existing relevant guiding theories}

College physical education includes many different types of subjects, such as management, anthropology, biology, physiology and economics. However, physical education is limited by teaching time, so it is impossible to teach all the subjects involved [7]. This requires us not only to actively absorb the original physical education theory, but also to combine with the development idea of modern physical education, the goal of higher physical education, people's all-round development, fitness and fitness, the development of modern sports and other diversified trends, so as to rebuild a more comprehensive and more characteristic college physical education theory system. The newly constructed system should include theoretical knowledge of human body, physiology, bodybuilding, sports skills and technology, think of sports, sports economy and culture, etc. The new physical theory system is not only a simple and mechanical make-up of various disciplines involved, but an organic integration of different disciplines. So that the new physical theory system can promote the all-round development of human beings, the physical and mental health, the social and economic development. In order to implement the new physical education theory system more scientifically, continuously and systematically, the content of physical education theory course should be reduced but not less than $30 \%$ without violating the basic principles of physical training,

\subsection{Promote the transformation of backward physical education teaching methods}

The traditional model of college physical education is to set teaching time and teach students in playgrounds or classes. Even though some changes have been made, the curriculum is still centered around the playground. In order to improve the overall effect of college physical education significantly, it is necessary to make more fundamental changes from educational ideas to teaching forms and teaching methods. Especially the physical education teaching can not only be fixed in the classroom, but in all sports behaviors and related activities such as the morning exercise activities carried out by the school, school-level and department-level sports competitions, sports team training, various teams and sports associations, various referee training activities, sports exchanges between different schools and between schools and the society, etc. This form is to put the university physical education teaching in a broader range of sports activities, that is known as "grand idea of sports." All the activities carried out by this concept have special theories as reference basis, which requires participants to prepare well in terms of quality and physique and implement the activities more systematically and effectively. More diversified and different levels of physical activities should be carried out in schools to make college sports safer, more scientific and healthier.

\subsection{Rationalization of course system and setting}

The college physical education course is definitely not just outdoor training, it should be more functional, richer in the content, more diversified in the form. At present, many physical education courses adopt the traditional outdoor sports training mode. The new physical education concepts are not integrated into the system, which leads to the unreasonable positioning of college physical education. Concretely, the existing 
physical education system in colleges and universities is lack of science. Therefore, the physical education curriculum teaching system should be actively optimized, which should include the following contents: experimental course, theoretical course, practical course, competition course, performance demonstration course, appreciation course, project training course and so on. After the construction of new curriculum system, the sports theory can be divided into practical knowledge, skills, knowledge, basic theory, humanistic sports, culture and economy, sports organization and management, etc. These ideas and practical courses are closely combined to make them with a strong flavor of Times, also makes physical education curriculum more vivid.

\subsection{Promote the development of students' comprehensive quality}

In the development of college physical education, in order to ensure the education quality of the cultivated talents, students need to develop a more perfect comprehensive quality. The students should not only have the basic theoretical knowledge and sports skills, but also pay attention to the cultivation of practical ability and social ability. Especially at present, sports competitions are becoming more and more popular. We should further improve the competitive sports mechanism, develop a more perfect management system, training system and enrollment system for students, and build a more perfect and systematic sports management system. It can not only help the society to train athletic talents, but also better achieve the ultimate goal of college physical education. The improvement of students' comprehensive quality requires teachers to closely combine theory with practice in teaching. The learning tasks formulated should also have the dual characteristics of theory and practice. Combined with the characteristics of physical education students' relatively weak cultural knowledge, enhance their cultural knowledge education, and optimize the way and target of talent training. Constructing a cultural course training plan for students, so that students' theoretical level will continue to improve. Through theoretical knowledge to guide the development of physical practice learning activities.

\section{CONCLUSION}

The reform of China's college physical education has been actively carried and achieved some results. However, there are still some problems, such as the separation of physical education curriculum from the market, poor comprehensive quality of students, backward teaching methods and so on. With the increasing demand for comprehensive sports talents in the current society, it is necessary to set up the "great idea of sports", combine physical education with various sports activities in daily life, and optimize the college physical education curriculum based on the market demand. At least we should make the trained sports talent meet the needs of society, so as to avoid the situation that students can't find a job and enterprises can't find suitable employees.

\section{REFERENCES}

[1] Wu Na. Discussion on Application of Flipped Classroom in College Physical Education Teaching [J]. Contemporary Sports Science and Technology,2020,10(33):94-95+98.

[2] HUANG Daihai. Discussion on the reform of college physical education under the thought of lifelong physical education [J]. Contemporary Sports Science and Technology,2020,10(32):3-5.

[3] Jin Hongwei. Research on College Physical Education Reform Based on Humanity Concern [J]. Contemporary Sports Science and Technology,2020,10(31):6-7+10.

[4] Jin Ding. Analysis of the problems existing in the reform of college physical education under the new situation [J]. Firework Technology and Market,2020(03):53.

[5] YUAN Yu. Discussion on the reform of physical education in colleges and universities [J]. Innovation Research of Ice and Snow Sports,2020(12):55-56. (in Chinese)

[6] Ma Baoan. Physical Education Teaching Reform and Innovation [J]. International Public Relations,2020(06):76+78.

[7] Chen Zhihua. Research on Higher Vocational Physical Education Reform Based on Quality Education [J]. Contemporary Sports Science and Technology,2020,10(17):16+18. 